\title{
Marketing Reform Interventions in the Performance of World Bank Financed Agricultural Programmes in Trans-Nzoia County, Kenya
}

\author{
Makokha Peter Wanyama $^{1}$, Dr. Lydia N. Wambugu² \& Prof. Peter Keiyoro ${ }^{2}$ \\ ${ }^{1}$ Program Quality Director-ETC Consulting-Nairobi, Kenya \& Quality Assurance Consultant-WWF \\ ${ }^{2}$ School of Open and Distance Learning, The University of Nairobi, Kenya \\ Correspondence: Makokha Peter Wanyama, Programme Quality Director-ETC Consulting-Nairobi, Kenya. E-mail: \\ drpetermakokha@gmail.com
}

Received: March 27, 2021

doi:10.5539/jsd.v14n3p136
Accepted: April 28, $2021 \quad$ Online Published: April 28, 2021

URL: https://doi.org/10.5539/jsd.v14n3p136

\begin{abstract}
The main objective of this study was examine contribution of marketing reform interventions on the performance of agricultural programmes funded by the World Bank in Trans-Nzoia County, Kenya. The study arose out of the need to quantify the worth of reform packages currently implemented in the agriculture sector thorough innovative interventions. The sample size of this study was 268 respondents determined using the simplified Yamane formula of proportions. Pragmatism school of thought was the best suited philosophy to guide this study as it complemented the epistemological, methodological and axiological underpinnings desired for mixed-mode research. Results obtained showed $\beta$ weight of 0.181 (F-value (0.029); $\rho$-value $=0.05$ ) implying that marketing reforms contributed positively to the performance of agricultural programmes. Further analysis generated $\mathrm{R}=0.125, \mathrm{R}^{2}=0.016$ and adjusted $\mathrm{R}^{2}=0.012$ indicating a better fit for the model and that marketing reform contributed to the performance of agricultural programmes by $1.6 \%$. The analysis also generated F- value $(0.029) ;(\mathrm{p}<0.05)$ and the F-calculated (4.796) being significantly larger than the critical value $(\mathrm{F}=2.454)$ suggesting up to $95 \%$ chance the model's strength in explaining it is statistically significant. These results support outcomes theory by providing documented analysis and empirical evidence to support the formulation of research-based policies and regulations. Findings from the study will therefore contribute immensely to the growth of project management discipline and agricultural marketing practices in Kenya and globally.
\end{abstract}

Keywords: programme management, marketing innovations, marketing intelligence, commodity marketing and performance of agricultural programmes

\section{Introduction}

Most African countries have, since the 1980s, liberalized agriculture, but the outcome of the reform process has been rather disappointing. Agricultural markets remain underdeveloped and inefficient as farmers continue to produce without much government support. While practitioners in commodity exchange opine that the continuous invigoration and re-engineering of marketing needs a proactive approach (Barrett \& Carter, 2013). Many reforms currently in use such as marketing in bulk through the cooperative societies, online sales and structured trading, lack a coherent strategy to ensure smallholder access. Again, there lacks empirical evidence to ascertain the impact of these approaches on emancipation from poverty and well-being. Whereas marketing interventions have been pioneered, their contribution to rural economies and enterprise growth in Kenya is not well documented.

Commodity marketing landscape in Kenya is premised on increasing returns by improving access to market infrastructure. Reformative efforts in the marketing sector require incessant navigation of myriad impossibilities to expand available space by adopting and venturing into innovative platforms. The World Bank pioneered the development of "Creating Markets Advisory Window" (CMAW); a reformative tool focusing on enhancing access. This tool has been lauded for enhancing the infrastructural development and supporting the commercialization of marketable surplus and productivity potential while emphasizing structured trading by re-orienting thin, fragmented and geographically dispersed markets into solid formidable structures (Jessa and Uys, 2019).

Given the nature of agricultural marketing and knowing full well that performance of the sector has been on the decline despite presence of large number of interventions, there is a need for introspection on the worth of interventions in use. Assessing the value of each of these interventions in the context of policy formulation, 
institutional capacity, market integration and the much needed research and technology are necessary. The outcome of this introspection is expected to bring the strongest and lasting impulses to food security and poverty reduction especially if paralleled with the concomitant approaches of participation, devolution and decentralization (Bisena and Kumar, 2018).

Quantifying marketing interventions is therefore critical in World Bank financed reforms, since it paints a picture of progress and justify the huge funding received in the sector. The programmes being examined in this study are implemented concurrently through the elaborate structure of the agriculture Ministry. Reforms envisioned under these programmes arose out of Structural Adjustment Programmes (SAPs) piloted by the Bretton Woods institutions that were meant to modernize agriculture and boost the productive capacity for developing countries. The reforms focus on increasing farm capacities by promoting agribusiness in value chains and technology adoption. Trans-Nzoia County was selected as de-facto environment for this study since it presented a perfect contextual environment for making inferences and a suitable scenario for mixed-mode research.

\subsection{Statement of the Problem}

A review of results from World Bank funded programmes indicated that poor performance was a major concern. It was found that $47 \%$ of funded interventions posted unsatisfactory results despite the adoption of many reforms (World Bank, 2019). Examples around the globe were unequivocal that project performance remained dismal in many interventions. In the UK, for instance, $23 \%$ of projects overshot their budgets, $20 \%$ were completed behind schedule while $7 \%$ under-delivered in scope. This phenomenon was replicated in USA where the average cost overrun was $17 \%$, time overrun, $15 \%$ and schedule overrun is $16 \%$.

Whereas a significant number of studies conducted to establish relationships between marketing and programme performance were emphatic, there exists variance in the nomenclature and operationalization of sub-variables encompassing marketing as a concept. This discrepancy has rendered role of marketing reform both inconclusive and incoherent. Studies done in India by (Pavithra, Gracy and Saxena, 2018) and (Kathuria, Singh and Raina, 2019), demonstrated the interactions between marketing reforms and performance. However, they were not tied to particular programmes but examined marketing in general. This study therefore differs from other contemporary works in terms of scope, context and complexity of the methodology.

\subsection{Study Objective}

To establish the extent to which marketing reform interventions influence the performance of World Bank financed agricultural programmes.

\subsection{Study Hypothesis}

The study tested the following null hypothesis:

Ho: There is no significant influence of marketing reform interventions on the performance of World Bank financed agricultural programmes.

\section{Literature Review}

Better access to marketing information and financial services are necessary preconditions to adoption of capital intensive, higher yielding technologies (Pavithra, Gracy, Saxena, 2018). Documented analysis on farm-level marketing in Kenya is limiting, however, it is worth noting that micro-credit provision alone does not guarantee sufficient support for agricultural transformation. Factors such as rapid training in post-harvest technology and assistance in establishing the storage and marketing facilities are crucial. Major challenge of implementing market reforms in Kenya has been to design and develop an input-output marketing structure that supports the sustainable increases in productivity for small-scale farmers while orienting them towards sustainable production. Marketing interventions therefore need to open up available market space and ensure that smallholders access consistent and reliable markets for their produce.

Amid the gloom of Kenya's rural business as usual or more accurately; the lack of it, a profound transformation has been underway for some time. Subsistence farming focused on household needs has become more diversified and better oriented towards markets (Pavithra, Gracy and Saxena, 2018). Under best mix of marketing conditions, the market-oriented transition could lead to the emergence of mixed-enterprise, with only a portion of the farm devoted for household production (Kathuria, Singh and Raina, 2019). This kind of transformation is not spontaneous but will result from favorable set of market conditions where farmers are empowered within their settings. This kind of transformation is desired in marketing reforms widely adopted by the World Bank in many Countries. Such reforms are expected to transform sectors and support concomitant efforts designed to boost productivity and increase shared prosperity.

In a study on the prospects for food security in Kenya, Keya, Kosura, Okeyo, Mwai and Kirina, (2019), using evidence from Five Counties and 200 marketing groups, found marketing interventions, diversification, processing 
and post-harvest processes potentially added value to the produce. This, in turn impacted development of surplus production that led to the adaptation of high yielding technologies. On the other hand, it is documented that successful investments in agriculture depend on technological development and consistency in the provision of essential services such as extension, training, value addition and credit provision. Middlemen, have been identified as greatest impediments to the development of agricultural marketing and that farm-gate prices offered by them were extremely low; a phenomenon that leads to dissatisfaction with the liberalization process.

A study on the role of agricultural cooperatives and credit policy reform in Uganda, focusing on opportunities for poverty reduction, Onyilo and Adong, (2019) demonstrated that smallholders experienced weak bargaining relationships vis-à-vis traders because they did not access information on price and alternative marketing channels. The study also showed that selling in bulk had given smallholders an opportunity to make profit. However, too often, smallholders were unable to fulfill contractual obligations, leading to their marginalization in the marketing space. This creates multiple consequences including unexploited production opportunities, post-harvest losses, price depression from seasonal gluts, unreliable quality control standards and ironically; unsatisfied demand. Reforming the marketing space was therefore designed to leverage smallholder farmers towards accessing most profitable markets.

Available empirical evidence show there exists avenues for overcoming constraints for pro-poor agricultural growth in the Sub-Saharan Africa. It is imperative that that poorer households and those living in remote areas tend to be poorly served by commodity markets (Keya, Kosura, Okeyo, Mwai and Kirina, 2019). However, such households lack sufficient purchasing power to establish profit-oriented enterprises, especially given their complex and many technical demands and high costs associated with penetrating markets. Smallholders therefore stand to benefit most from assistance in post-harvest handling and communal storage and marketing of collective surplus. Most marketing trends in Africa are changing fast, leading to emergence of supermarkets and cereal banks in many parts thereby providing new markets. These continuous re-engineering of composition and architecture of commodity markets in developing countries is therefore what World Bank desired through the many reform interventions pioneered.

\subsection{Theoretical Framework}

This study was supported by the outcomes theory, developed by Paul Duignan in 2008 as a conceptual basis for thinking about and working with outcome systems in interventions. This theory supported the predictive variable and anchors the aspects of programme performance. This theory helps identify, prioritize, measure or holds parties in any programme process to account for results generated for each intervention (Schieber, 2017). This theory underscores the importance of development outcomes in consolidating the role of strategic plans, management by results and results-based management systems in programme delivery.

\subsection{Conceptual Framework}

For this study, the conceptual framework focused on two prime variables as per Figure 1. The study contained many indicators under both variables. Indicators for marketing reform were thought to influence the dependent variable. For this reason, all the indicators under the independent variable were tested to examine their strength on the dependent variable.

\section{Dependent Variable}

\section{Independent Variable}

\begin{tabular}{|ll|}
\hline - & \multicolumn{1}{c|}{ Marketing Reform } \\
- & Ease of access to markets, \\
- & Marketing regulations \\
- & Distance to markets, \\
- & on-line market intelligence, \\
- & Market space, \\
- & Market associations and groups, \\
- & Marketing models \\
\hline
\end{tabular}

Performance of Agricultural Programmes Funded by World Bank

- Satisfactory production

- Prescribed quality

- Surplus production

- Anticipated profits

- Satisfactory income

- Produce safety

- Post-harvest security

- Positive feedback

- Post-harvest safety

- Productive capacity

Figure 1. Conceptual framework for marketing reform and performance of programmes funded by the World Bank 


\section{Methodology}

This research study was guided by pragmatism paradigm considering that it adopted mixed method approach in data collection and analysis. Pragmatism paradigm accommodates both constructivist and positivist philosophies and it was subsequently expended in this study to support the descriptive survey design. Qualitative data was collected though interview guide and focus groups administered to key implementers. Target population was 800 farmers and 15 extension officials. Sample size was 268 respondents determined by the simplified Yamane formula, expressed as follows:

$$
\mathrm{n}=\frac{N}{1+N(e)^{2}}
$$

Where,

$\mathrm{n}=$ Sample size required,

$\mathrm{N}=$ Number of people in the population (target population)

$\mathrm{e}=$ Allowable error (error term)

\section{Findings and Discussions}

In this study, descriptive research design anchored on principles of mixed-mode research approach were expended. Where else descriptive and inferential analysis in addition to the qualitative statistical examination were conducted simultaneously. Descriptive analysis in support of the research objective was executed foremost by testing central tendency (mean as well as standard deviation) then trailed by inferential analysis using the person's product moment correlation, linear regression and analysis of variance (ANOVA).

\subsection{Questionnaire Response Rate}

Out of the 268 questionnaires administered, 255 were filled and returned. This represents a response rate of $95.14 \%$ tabulated as shown in Table 1.

Table 1. Questionnaire response rate

\begin{tabular}{llll}
\hline Cluster & Sample Size (n) & No Returned & Response Rate (\%) \\
\hline Cherangany & 38 & 36 & 94 \\
Endebess & 37 & 34 & 92 \\
Central & 34 & 34 & 97 \\
Kaplamai & 33 & 31 & 90 \\
Kiminini & 43 & 40 & 93 \\
Kwanza & 38 & 37 & 94 \\
Saboti & 40 & 38 & 96 \\
Extension staff & 3 & 3 & 100 \\
Programme officials & 2 & 2 & 100 \\
\hline Total & $\mathbf{2 6 8}$ & $\mathbf{2 5 5}$ & $\mathbf{9 5 . 1 4}$ \\
\hline
\end{tabular}

\subsection{Distribution of Respondents by Gender}

Results on the composition of gender are presented in Table 2.

Table 2. Distribution of respondents by gender

\begin{tabular}{lll}
\hline Gender & Frequency & Percentage \\
\hline Female & 93 & 36.3 \\
Male & 142 & 55.9 \\
\hline Total & $\mathbf{2 5 5}$ & $\mathbf{1 0 0}$ \\
\hline
\end{tabular}




\subsection{Distribution of Respondents by Age}

Results on the distribution of respondents by age are presented in Table 3 .

Table 3. Distribution of respondents by age

\begin{tabular}{lll}
\hline Age & Frequency & Percentage \\
\hline 20-25 Years & 15 & 5.9 \\
26-30 Years & 0 & 0 \\
31-35 Years & 45 & 17.6 \\
36-40 Years & 57 & 22.5 \\
Above 40 Years & 138 & 53.9 \\
\hline Total & $\mathbf{2 5 5}$ & $\mathbf{1 0 0}$ \\
\hline
\end{tabular}

4.4 Distribution of Respondents by Highest Level of Education

Results on distribution of respondents by the highest level of education are illustrated in Table 4 .

Table 4. Distribution of respondents by highest level of education

\begin{tabular}{lll}
\hline Highest Level of Education & Frequency & Percentage \\
\hline No formal education & 12 & 4.9 \\
Primary school level & 120 & 47.1 \\
Secondary school level & 105 & 41.2 \\
Certificate level & 15 & 5.9 \\
Diploma level & 3 & 1 \\
\hline Total & $\mathbf{2 5 5}$ & $\mathbf{1 0 0}$ \\
\hline
\end{tabular}

\subsection{Distribution of Respondents by Level of Literacy}

Results are presented in Table 5.

Table 5. Distribution of respondents by level of literacy

\begin{tabular}{lll}
\hline Level of Literacy & Frequency & Percentage \\
\hline Can Read & 5 & 2 \\
Can Write & 10 & 3.9 \\
Can Read and Write & 215 & 84.3 \\
Cannot Read and Write & 23 & 8.8 \\
Missing Response & 2 & 1 \\
\hline Total & $\mathbf{2 5 5}$ & $\mathbf{1 0 0}$ \\
\hline
\end{tabular}

4.6 Distribution of Respondents by Primary Farming Occupation

Results on distribution of respondents by farming occupation are presented in Table 6 
Table 6. Distribution of respondents by primary farming occupation

\begin{tabular}{lll}
\hline Farming Occupation & Frequency & Percentage \\
\hline Maize farmer & 110 & 43.1 \\
Livestock farmer & 40 & 15.7 \\
Crop farmer & 13 & 4.9 \\
Livestock marketer & 55 & 21.6 \\
Horticultural trader & 15 & 5.9 \\
Banana farmer & 22 & 8.8 \\
\hline Total & $\mathbf{2 5 5}$ & $\mathbf{1 0 0}$ \\
\hline
\end{tabular}

\subsection{Treatment and Decision Rule for Likert-Scale}

Depending on how likert-scale questions were treated, a number of different analysis methods could apply. While it is becoming a common practice for researchers to assume that likert-type questions constitute interval-level measurement, still certain assumptions have to be met. Use of non-parametric tests are preferred where the data is clearly ordinal, but where the researcher is confident that data can be justified as interval, attention should shift to the sample size and to the normality of the distribution. As a matter of fact, sample size and normality of the distribution are considered more important than level of measurement in determining whether it was appropriate to use the parametric tests as corroborated by Creswell, (2012) or inferential statistics. This notwithstanding, preferred statistical method to analyze the likert-type data depends on nature of their non-equidistance as well as their skewness. Guest, (2013) opines that parametric methods can be used to analyze data that is not equidistant by nature. Likert-type data is assumed to be equidistant by applied researchers so that the parametric methods can be applied in subsequent analysis. In general, perceived distance between scale points on a regular five-point likerttype scale depends on how anchors were deployed.

\subsection{Normality Test}

The variables were further subjected to the test of normality to determine whether the distribution was normal. This was conducted thorough the Kolmogorov-Smirnov (K-S) test and the Shapiro-Wilk (S-W) test, both based on the largest vertical difference between the hypothesized and the empirical distribution. Findings on normality are presented in Table 7.

Table 7. Test of normality

\begin{tabular}{lllllll}
\hline Variable & \multicolumn{3}{l}{ Kolmogorov-Smirnova } & \multicolumn{3}{l}{ Shapiro-Wilk } \\
\cline { 2 - 7 } & Statistic & df & Sig. & Statistic & df & Sig. \\
\hline Performance of Agricultural Programmes & 0.123 & 245 & $0.121^{*}$ & 0.966 & 245 & $0.212^{*}$ \\
Marketing Reform & 0.11 & 243 & $0.376^{*}$ & 0.927 & 243 & $0.510^{*}$ \\
\hline
\end{tabular}

Findings from K-S test obtained indicated highly significant variables and showed that parameters were approximately normally distributed. A significant value of less than 0.05 indicates a deviation from normality.

\subsection{Multicollinearity and Heteroscedasticity}

The study variables were subjected to multicollinearity testing using the Variance Inflation Factor (VIF) and tolerance tests in regression analysis. Findings are presented in Table 8

Table 8 . Test of multicollinearity

\begin{tabular}{lll}
\hline Coefficient Variable & Collinearity Tolerance & Statistics VIF \\
\hline Marketing Reform (Mean) & 0.388 & 2.577 \\
\hline Dependent Variable: Performance of Agricultural Programmes funded by the World Bank
\end{tabular}

Results in Table 8 show that the VIF factor was 2.577, which is within the set criteria set by the rule of thumb that suggests that VIF should be less than 10 . Tolerance value was 0.388 that is also within the set criteria. Tolerance 
values of less than 0.1 infers multicollinearity. Since the tolerance value for the independent variable was 0.388 , this then infers there was no multicollinearity.

\subsection{Qualitative Analysis of Marketing Reform Interventions}

Indicators to measure marketing reform were; market location, ease of access to physical markets, regulations governing commodity markets, distance to markets, access to market intelligence, composition and availability of markets, online markets access, availability of marketing space, associations and groups, marketing models and complexity associated with markets. The descriptive results are shown in Table 9.

Table 9. Descriptive results of marketing reform interventions

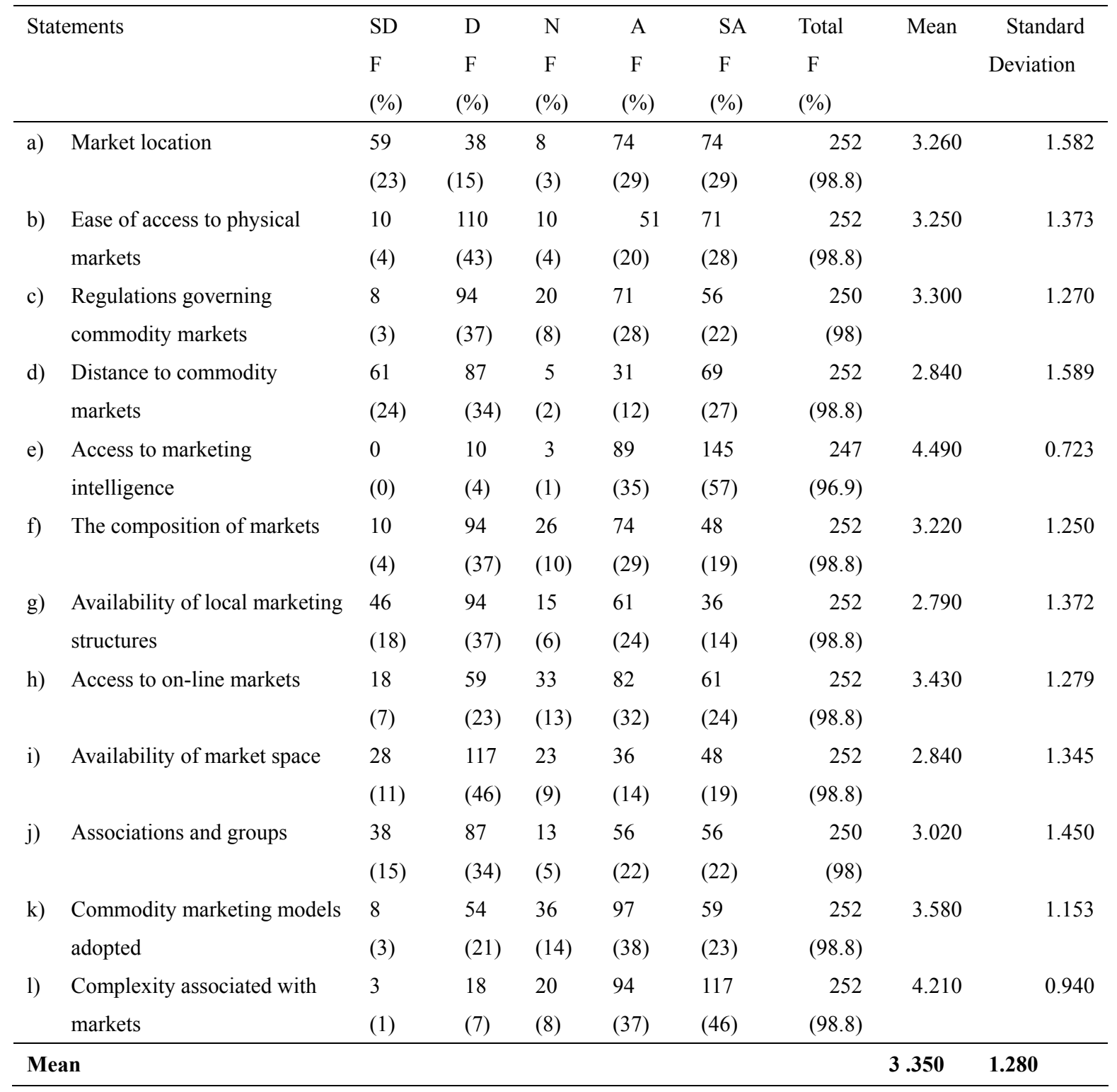

The composite mean was found to be $(\mathrm{M}=3.350)$ and composite standard deviation $(\mathrm{SD}=1.280)$. These results show that respondents were neutral to most of the statements on marketing reform. Lower levels of standard deviation in these results imply that respondents held divergent views on indicators used to measure marketing reform.

\subsection{Qualitative Analysis of Performance of Agricultural Programmes}

Indicators to measure the performance of programmes were; satisfactory production, prescribed quality, surplus production, anticipated profits, satisfactory income, produce safety, post-harvest security, productive capacity, 
positive feedback, stable produce prices, encouraged farmers and post-harvest safety. The qualitative results were as shown in Table 10.

Table 10. Qualitative results on the performance of agricultural programmes

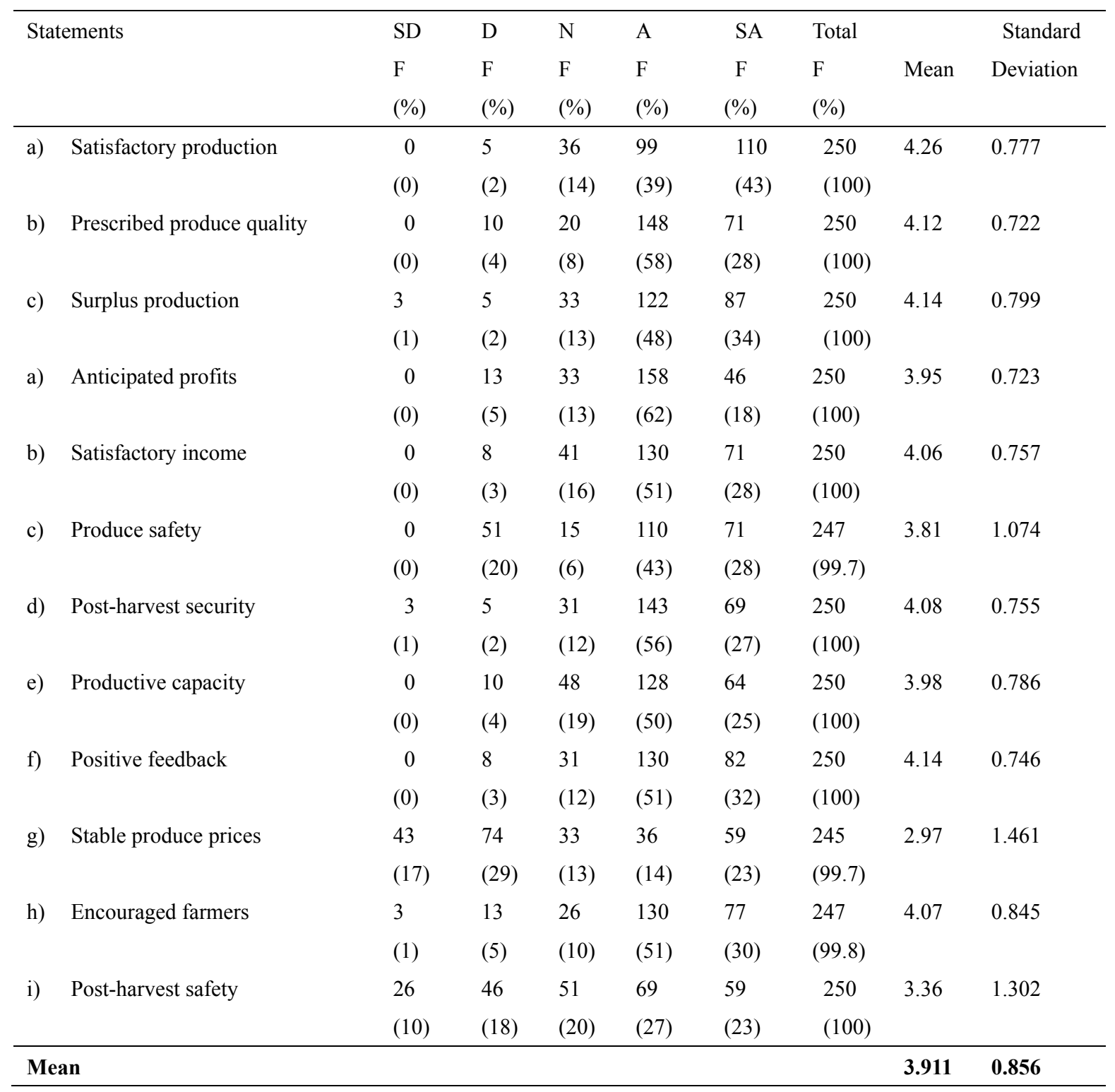

Results from the composite mean $(\mathrm{M}=3.91)$ and standard deviation $(\mathrm{SD}=0.856)$ imply that respondents agreed to most statements used to measure the performance of agricultural programmes. Results show responses were not scattered from the mean as characterized by the small standard deviation. This means respondents were of the same mind on most parameters used to measure the performance of agricultural programmes.

\subsection{Correlation between Marketing Reform and Performance of Agricultural Programmes}

Results of the correlation to establish the direction and the magnitude of the relationship between marketing reform interventions and the performance of agricultural programmes are shown on Table 11: 
Table 11. Correlation between marketing reform and performance of agricultural programmes

\begin{tabular}{llrrr}
\hline Variable & Marketing & reform & $\begin{array}{r}\text { Performance of agricultural } \\
\text { programmes }\end{array}$ \\
\hline Marketing reform & Pearson Correlation & & 1 & $0.125^{*}$ \\
interventions & Sig. (2-Tailed) & & & 0.029 \\
& $\mathrm{n}$ & 255 & 255 \\
Performance & of & Pearson Correlation & $0.125^{*}$ & 1 \\
agricultural & Sig. (2-Tailed) & 0.029 & \\
programmes & $\mathrm{n}$ & 255 & 255 \\
\hline
\end{tabular}

*. Correlation is significant at the 0.05 level (2-tailed)

Results on correlation between marketing reform interventions and the performance of agricultural programmes reveal a weak positive correlation of 0.125 . A significant relationship with p-value of 0.029 found to be far less than the test level of significance (0.05). This indicates that marketing reform has a significant influence on the performance of agricultural programmes funded by the World Bank.

\subsection{Inferential Analysis}

In order to establish causality between the independent and dependent variables, a regression model and the analysis of variance (ANOVA) were run using the statistical package for social sciences (SPSS). Regression was conducted to determine whether there existed a statistical relationship between indicators under the independent variable and the performance of agricultural programmes funded by the World Bank. The analysis of this relationship coincides with testing of the hypothesis. The results were discussed as per the study hypothesis as follows:

\subsection{Hypothesis}

The hypothesis coincided with the objective of this study which was:

Establish extent to which marketing reform interventions influence the performance of agricultural programmes funded by World Bank in Trans-Nzoia County, Kenya.

The null hypothesis was:

$\mathrm{Ho}_{1}$ : There is no significant influence of marketing reform interventions on the performance of agricultural programmes funded by the World Bank in Trans-Nzoia County. To test this hypothesis a regression model of marketing reforms on performance of agricultural programmes was run.

Table 12. Model summary

\begin{tabular}{lllll}
\hline Model & R & R Square & Adjusted R Square & Std. Error of the Estimate \\
\hline 1 & $0.125^{\mathrm{a}}$ & 0.016 & 0.012 & 7.686 \\
\hline
\end{tabular}

a. Predictors: (Constant), Marketing Reform

b. Dependent Variable: Performance of Agricultural Programmes

Table 13. ANOVA

\begin{tabular}{llllll}
\hline Factor & Sum of Squares & df & Mean Square & F & Sig. \\
\hline Regression & 283.330 & 1 & 283.330 & 4.796 & 0.029 \\
Residual & 17957.589 & 254 & 59.071 & & \\
\hline Total & $\mathbf{1 8 2 4 0 . 9 1 8}$ & $\mathbf{2 5 5}$ & & & \\
\hline
\end{tabular}

a. Predictors: (Constant), Marketing Reform

b. Dependent Variable: Performance of Agricultural Programmes

The inferential analysis using regression shows an $\mathrm{R}=0.125, \mathrm{R}^{2}=0.016$ and adjusted $\mathrm{R}^{2}=0.012$. This provides an 
explanation on the extent to which marketing reform accounts for the overall variability of the model. $\mathrm{R}^{2}=0.016$ indicates that marketing reform contributed to performance of agricultural programmes by $1.6 \%$. We deduce that marketing reform interventions have a significant influence on the performance of agricultural programmes funded by the World Bank. Analysis of variance established the goodness of fit of the regression model, that the F- value $(0.029)$ was less than $(\mathrm{p}<0.05)$. The F-calculated (4.796) was significantly larger than the critical value $(\mathrm{F}=2.454)$. We therefore deduce that the model is statistically significant.

\section{Conclusions and Recommendations}

The findings of this study are mainly based on the F statistic which helps determine if there is a significant relationship between response variable and the predictive variable. The F-statistic was judged based on the p-value. In the event the p-value was less than 0.05 , it was an implication that the F-statistic was statistically significant; a further implication that the independent variable statistically explained the dependent variable. Since the F- value was $(0.029)$, far less than $(\mathrm{p}<0.05)$ and the F-calculated $(4.796)$ was significantly larger than the critical value $(\mathrm{F}=2.454)$, this therefore means that the model is statistically significant.

From the objective of this study as per the aforementioned the null hypothesis tested was; There is no significant influence of marketing reform interventions on performance of agricultural programmes funded by the World Bank Results obtained; F-value (0.029) less than $(\mathrm{p}<0.05), \mathrm{R}=0.125, \mathrm{R}^{2}=0.016$. The correlation coefficient $(0.125)$ was moderately low, even though it was positive. The F-statistic, however was found to be statistically significant; an implication that the null hypothesis is rejected. From these findings, we conclude there is a significant relationship between marketing reform interventions and the performance of agricultural programmes funded by the World Bank in Trans-Nzoia County. The study therefore supports the view that more commodity marketing efforts need to be put in place if the agriculture sector in Kenya has to be revitalized.

Considering that the government of Kenya is working to develop systems and structures to ensure that development projects and programmes are delivered within the confines of time, cost, resources and client satisfaction, this study has implications to policy framework in general. The findings show that reforms are critical in bettering the performance of programmes and development initiatives in general. These findings would ordinarily impact the policy framework as they provide empirical data critical in supporting research-based policy formulation. Policy makers would use these findings to formulate policies backed by empirical reasoning. Legislative and regulatory bodies, including houses of parliament at national and county level will find these research a useful masterpiece.

\subsection{Summary of the Test Hypothesis}

The summary of test hypothesis and results are described as follows;

Table 14. Test of hypothesis and results

\begin{tabular}{|c|c|c|c|}
\hline Objective & Hypothesis & Results & Conclusions \\
\hline \multirow{4}{*}{$\begin{array}{l}\text { Establish the extent to } \\
\text { which marketing reform } \\
\text { interventions influence } \\
\text { the performance of World } \\
\text { Bank financed projects }\end{array}$} & Ho1: & F- value $(0.029)$ & \multirow{4}{*}{$\begin{array}{lrr}\text { Reject } & \text { the } & \text { null } \\
\text { hypotheses. } & \text { The } \\
\text { correlation } & \text { coefficient } \\
(\mathrm{r}=0.125) & & \text { was } \\
\text { moderately } & \text { low } & \text { and } \\
\text { positive. } & & \\
\end{array}$} \\
\hline & $\begin{array}{l}\text { There is no significant } \\
\text { influence of marketing }\end{array}$ & $\mathrm{P}=0.0025<0.05$ & \\
\hline & reform interventions on & & \\
\hline & Bank financed projects & $\mathrm{R}=0.125$ & \\
\hline
\end{tabular}

$\mathrm{R}^{2}=0.016$

In running the regression model, the most significant variables were market location, availability of marketing structures and availability of marketing space. In essence, most indicators under marketing reform interventions were observed to be important explanatory variables for performance of agricultural programmes funded by the World Bank in Trans-Nzoia County prompting the rejection of the null hypothesis.

\section{References}

Adegbidi, A. (2012). Impacts of ICT use on access to markets by pineapple small holder farmers in Benin. Journal of Research in International Business Management.

Almalki, S. (2016). Integrating quantitative \& qualitative data in mixed methods research: challenges and benefits. https://doi.org/10.5539/jel.v5n3p288

ASDSP. (2011). Agriculture Sector Development Support Program. Government of Kenya, Nairobi, (Government 
Printer).

Barrett, C. (2008). Smallholder market participation, concepts and evidence from East and Southern Africa. Food Policy. https://doi.org/10.1016/j.foodpol.2007.10.005

Barrett, C., \& Carter, M. (2013). Economics of poverty traps and persistent poverty; empirical and policy implications. Journal of development studies. https://doi.org/10.1080/00220388.2013.785527

Bisena, J., \& Kumar, R. (2018). Agricultural marketing reforms and e-national agricultural market (e-NAM). Agricultural Economics Research. https://doi.org/10.5958/0974-0279.2018.00032.0

Creswell, J. W. (2012). Educational research: Planning, conducting, and evaluating Quantitative and qualitative research. Upper Saddle River, NJ: Prentice Hall.

Creswell, J. W., \& Plano Clark, V. L. (2011). Designing and conducting mixed methods research. Sage, Los Angeles.

Duignan, P. (2009). Using outcomes theory to solve important conceptual and practical problems in evaluation, monitoring and performance measurement.

Guest, G. (2013). Describing mixed methods research, an alternative to typologies. Journal of mixed methods research. https://doi.org/10.1177/1558689812461179

Keya, S. O., Kosura, W. O., Okeyo Mwai, A., \& Kirina, T. K. (2019). Prospects for food security in Kenya: Evidence from Five Counties.

McKim, C. A. (2017). The value of mixed methods research: Mixed methods study. Journal of Mixed Methods Research. https://doi.org/10.1177/1558689815607096

Onyilo, F., \& Adong (2019). Agricultural cooperative marketing and credit policy reform in Uganda: An opportunity for poverty reduction. African Journal of Food, Agriculture and Nutrition. https://doi.org/10.18697/ajfand.84.BLFB1008

Pavithra, S., Gracy, C. P., \& Saxena, R. (2018). Innovations in agricultural marketing: A case study of e-tendering system in Karnataka, India. Agricultural Economics. https://doi.org/10.5958/0974-0279.2018.00005.8

Ralston, S. (Ed.). (2013). Philosophical pragmatism and international relations: Essays for a bold new world. Cornell University Press.

Sekaran, U. (2000). Research methods for business: A skill building approach. John Wiley.

Shannon-Baker, P. (2016). Making paradigms meaningful in mixed methods research. Journal of Mixed Methods Research. https://doi.org/10.1177/1558689815575861

World Bank. (2019). Complexity of managing reform interventions in the context of developing economies.

\section{Copyrights}

Copyright for this article is retained by the author(s), with first publication rights granted to the journal.

This is an open-access article distributed under the terms and conditions of the Creative Commons Attribution license (http://creativecommons.org/licenses/by/4.0/). 